\title{
Research on Ultimate Strength of Hull Structure Based on Cumulative Plastic
}

\author{
Guochun Lu' ${ }^{1,2, a}$, Huilong Ren ${ }^{1, b}$ and Guannan $\mathrm{Chu}^{2, \mathrm{c}}$ \\ ${ }^{1}$ College of Shipbuilding Engineering, Harbin Engineering University, Harbin, 150001, China \\ ${ }^{2}$ School of Naval Architecture and Ocean Engineering, Harbin Institute of Technology at Weihai, \\ Weihai, 264209, China \\ amslgc@qq.com, renhuilong@263.net, chuguannan@163.com
}

Keywords: stiffened plates, cyclic loads, ultimate strength, NLFEA, cumulative plastic.

Abstract. The ultimate strength of hull structure becomes more and more important in the whole life cycle. Many ways of assessment are developed in the design stage and the calculation accuracy can meet the need of safety. However, all methods of assessment are based on one-time collapse. This certain method is in conflict with the random of wave environment. In this paper, stiffened plates with cyclic loads are researched. The ultimate strength, which considers cumulative plastic, is simulated by NLFEA. The results indicate that the assessment criteria based on one-time collapse may magnify the actual ultimate capacity. This will be very important to research the sea damage in non-extreme environment.

\section{Introduction}

With the development of global maritime industry, the large scale of ship dimensions and the magnification of shipping scopes took new challenges to the safety of ship structure. Classical methods of strength check could not meet the new reality. Then the ultimate strength was presented to describe the ultimate capacity of hull. Paik ${ }^{[1]}, \mathrm{YaO}^{[2]}$ and Gordo $^{[3]}$ defined the ultimate strength based on one-time collapse. Many engineering factors, including residual stresses, deformations, loads and dimensions, were researched to analyze influences on the ultimate strength. This assessment criteria took a great reduction for sea accidents. But the Japanese 56340DWT bulk carrier named Onomichi collapsed under severe sea condition in 1980. According to one-time collapse, the calculation strength could resist the sea condition. This mean classical method overestimated the actual strength. Then cyclic loads were taken account into the ultimate calculation. By mid-1980s, Fukumoto and Kusama ${ }^{[4]}$ analyzed the non-elastic deformation of welded box structure under cyclic loading. In 1990s, Huang ${ }^{[5]}$ analyzed the load bearing capacity of plates under in-plane cyclic loading through theoretical and experimental investigations. In 2007s, Ren ${ }^{[6]}$ analyzed the ultimate strength with various load paths by considering cumulative plastic, which was caused by multiple plastic process. In 2014s, Yang ${ }^{[7]}$ took serial tests to verify the influence of cyclic load on box girders. All conclusions indicated the overall collapse would happen although actual strength was smaller than the calculation ultimate capacity when the wave loads were large and cyclic on the hull. The stiffened plates were basic elements of hull structure. The study on cyclic performance of ship plates is important for further understanding of failure mechanism of ship structures under cyclic bending moment. This paper investigates the ultimate strength and mechanical performance of stiffened plates by numerical ways, and some useful conclusions are drawn from the results.

\section{Description of the Model}

The physical model came from stiffened plates. So, a stiffened plate of size $2550 \mathrm{~mm} \times 850 \mathrm{~mm}$ was considered for the study. The thickness of plate was $11 \mathrm{~mm}$. The stiffener was taken $\mathrm{T}$ section with $235 \mathrm{~mm} \times 10 \mathrm{~mm} / 90 \mathrm{~mm} \times 15 \mathrm{~mm}$. The yield strength of material is assumed as $315 \mathrm{~N} / \mathrm{mm}^{2}$ with Young's modulus of elasticity(E) as $205800 \mathrm{~N} / \mathrm{mm}^{2}$. Elastic perfectly plastic was adopted for hardening rules. The deflections factor was taken by Eq.1. and Eq.2. 


$$
\begin{aligned}
& \beta=\frac{b}{t} \sqrt{\frac{\sigma_{y}}{E}} . \\
& w=0.1 \beta^{2} t .
\end{aligned}
$$

\section{NLFEA Simulation}

According to the geometrical dimensions and material properties, this paper used ABAQUS to simulate the process of cyclic loading. During building models, there were three aspects to ensure the simulation meet the actual model. First, MPC constraint must be used to ensure the line boundary conditions. The stiffened plates of hull structure were not isolated, because boundaries of plates were supported by stiffeners. Nodes of boundary must be coordinated by the multi-point constraint. Especially, unloading boundaries must keep straight. Second, eigenvalue buckling must be used to apply the initial deflections.This could be used keywords to come true. At last, Both geometric and material nonlinearities are considered in the analysis. Thus, the Riks Method was used to trace the post-buckling process.

Cyclic loads could be defined by tension-compressive loads. The load path was started by compressive load. Table 1 showed three load case which varied from load path.

Table 1 Load Case of Cyclic Load

\begin{tabular}{cccccc}
\hline & First & First & Compressive & Tensile & \\
Load Case & Compression & Tension & Increment & Increment & Cyclic count \\
& $\varepsilon / \varepsilon_{y}$ & $\varepsilon / \varepsilon_{y}$ & $\varepsilon / \varepsilon_{y}$ & $\varepsilon / \varepsilon_{y}$ & \\
\hline LC1 & 2 & 0 & 0 & 0 & 1 \\
LC2 & 1 & 0.5 & 0.25 & 0.125 & 4 \\
LC3 & 1 & 0.5 & 0.25 & 0 & 4 \\
LC4 & 1 & 0.5 & 0.25 & 0.25 & 4 \\
\hline
\end{tabular}

LC1 calculated the ultimate strength of stiffened plate with no cyclic load. The result was used to compare the others of cyclic load. LC2 4 took cyclic load in account. At the same time, the change of tension was analyzed to compare various load paths. In this paper, tension was only used to simulate the wave load. The Bauschinger Effect was not included .

Fig. 1 showed the stress strain curve of LC1. The ultimate strength of one-time collapse was 169.35MPa. The curve illustrated that the ultimate capacity declined quickly in the process of post buckling.

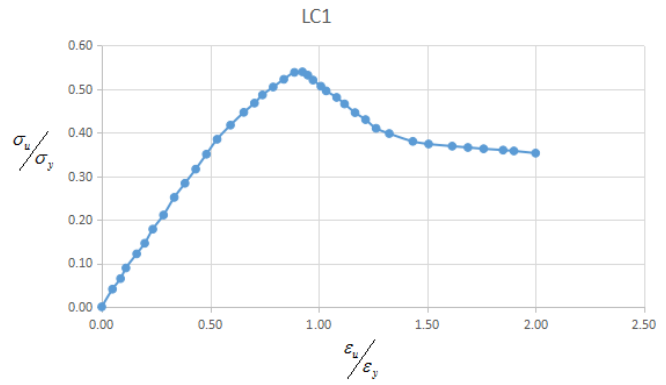

Fig.1 Stress strain curve of LC1

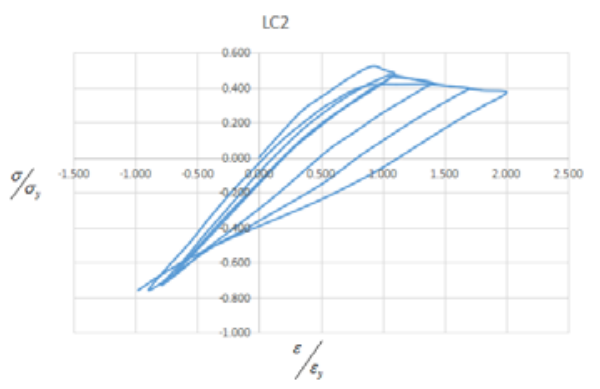

Fig.2 Stress strain curve of LC3 


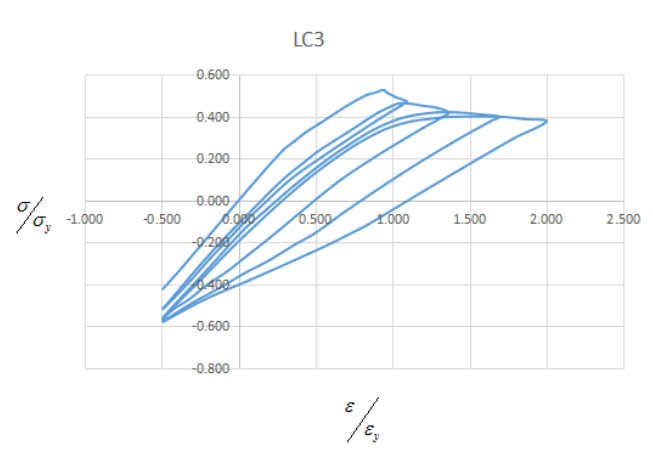

Fig.3 Stress strain curve of LC3

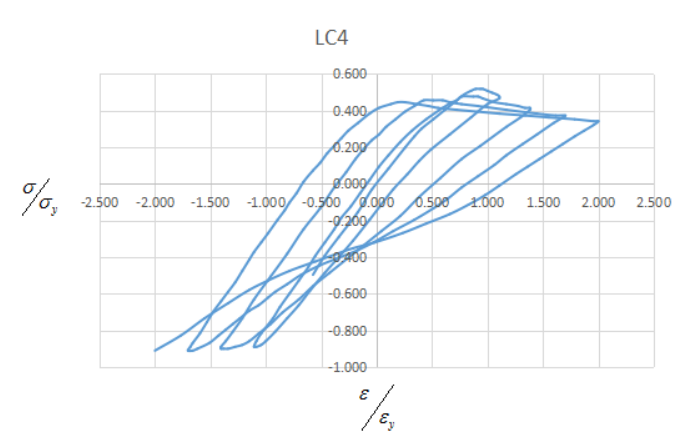

Fig.4 Stress strain curve of LC4

Fig.2, Fig.3 and Fig.4 showed the same conclusion that the ultimate strength would decrease with once cycle. In other word, when the stiffened plate suffered plastic deflections, the influence of damage could not disappear. The plastic deflections were accumulated in very cycle until it exceeded its ultimate bear capacity. Table 2 showed the differences among very load case and very cycle. On the other hand, the influence of tension could not be ignored. The increment ratio of ultimate strength may approach $15 \%$ by comparison. When the stiffened plate suffered tension, residual stresses and plastic deflections would decrease. But if the tension was too big to make the plate thin, the result will change.

Table 2 Ultimate strength comparison of different load case $\left[\mathrm{N} / \mathrm{mm}^{2}\right]$

\begin{tabular}{cccc}
\hline & LC2 & LC3 & LC4 \\
\hline First Cycle & 169.35 & 169.35 & 169.35 \\
Second Cycle & 153.60 & 146.80 & 147.20 \\
Third Cycle & 142.35 & 127.63 & 135.22 \\
Last Cycle & 136.93 & 119.72 & 127.41 \\
\hline
\end{tabular}

From observation to the simulation of cyclic load process, it revealed the reasons why the ultimate strength would continuously reduce after every cyclic loading. On one hand, the stiffened plate suffered buckle in every loading process. This was the main failure mode of the stiffened plate. The structure would collapse quickly after buckle, especially in post-buckle stage. On the other hand, the material yielding reduced the bear capacity.From Fig.5 to Fig. 8, the red contour mean that the material had been yielded. Because the Young's module in elastic stage was much bigger than it in plastic stage. Thus, the failure departments could not undertake the external load and these load must be applied by other departments. At last, deflections had a great influence to the ultimate strength. This had been proved by early researches. When material yielding and buckling happened, plastic deflections were inevitable. The accumulated platic deflections would reduce the bear capacity greatly.

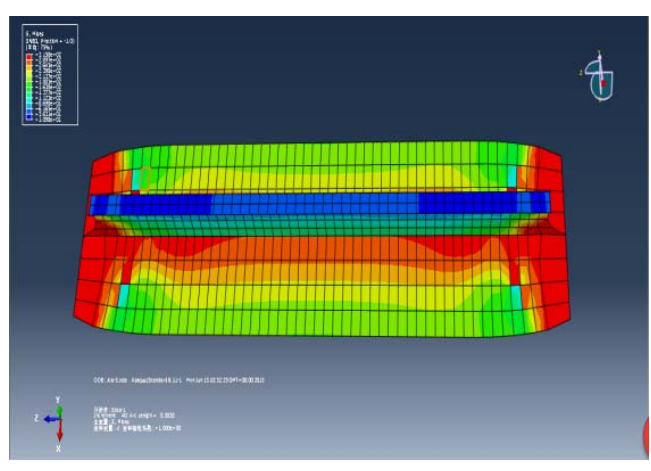

Fig.5 Stress contour plot of the first cycle

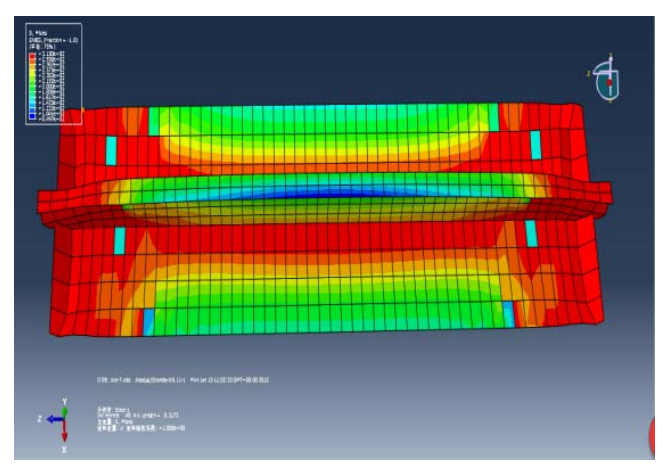

Fig.6 Stress contour plot of the second cycle 


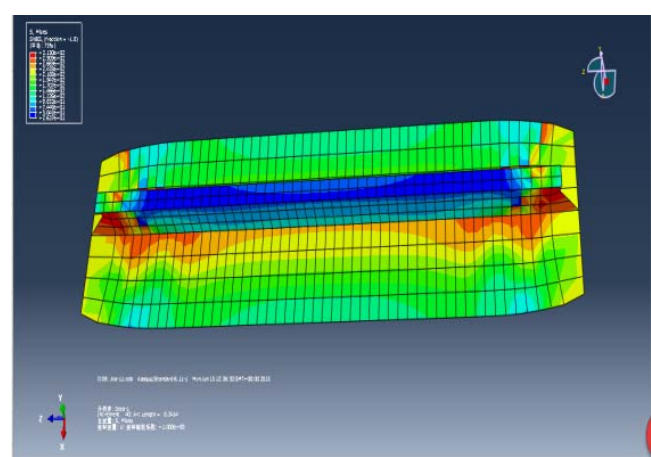

Fig.7 Stress contour plot of the third cycle

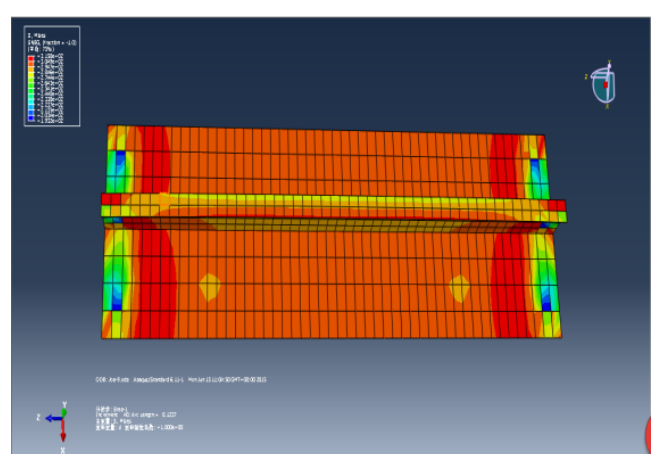

Fig.8 Stress contour plot of the fourth cycle

\section{Summary}

The cyclic loads had a great influence on the ultimate strength of stiffened plate. With the increasing of cyclic loads, the ultimate strength of stiffened plate kept decreasing. In the research, the load path was very important to calculate the ultimate strength. Different paths would lead different results. In view of periodic wave loads, it would be important for further ship design. In this paper, the ultimate strength gained by one-time collapse was same as the cyclic loads, because displacement incremental iterative was adopted to apply loads. If the start load was less than the ultimate capacity and the material reached the plastic state, the results between one-time collapse and cyclic loads were same or not. This problem would be taken account.

\section{Acknowledgments}

This work was financially supported by the Natural Science Foundation of China (51409073).

\section{References}

[1] Paik J K, Kim B J, Seo J K. Methods for ultimate limit state assessment of ships and ship-shaped offshore structures: Part III hull girders[J]. Ocean Engineering, 2008(35): 281-286.

[2] Yao T, Nikolov P I. Buckling/plastic collapse of plates under cyclic loading [J]. Journal of the Society of Naval Architects of Japan, 1990, 168: 449-462.

[3] Guedes Soares, C. Design Equation for Ship Plate Elements under Uniaxial Compression, Journal of Constructional Steel Research, 1992, 22: 99-114.

[4] Fukumto Y, Kusama H. Cyclic behavior of plates under in-plane loading[J]. Engineering Structures, 1985, 7: 56-63.

[5] Huang Z Q. Ultimate strength of a rectangular plate under cyclic compressive and tensile loads[J]. Journal of Huazhong University of Science and Technology (Natural Science Edition), 1994 (04): 36-41. (in Chinese)

[6] Ren Huilong, Li Chenfeng. Research of the hull ultimate strength based on the incremental plastic damage [J]. Ship mechanics academic meeting, China, 2007, 337-342.

[7] YANG Ping, CUI Hu-wei, DAI Yin-ze etl.Experimental and Numerical Investigations on Ultimate Strength of Ship Plates under Longitudinal Cyclic Loads [J]. Journal of Ship Mechanics, China, 2014,18: 1100-1108. 